\title{
Pedro SÁNCHEZ-PRIETO (coord.), ALFONSO X EL SABIO, General Estoria
}

José Carlos Miranda e Mariana Leite

\section{(2) OpenEdition}

1 Journals

\section{Edição electrónica}

URL: http://journals.openedition.org/medievalista/619

DOI: 10.4000/medievalista.619

ISSN: 1646-740X

\section{Editora}

Instituto de Estudos Medievais - FCSH-UNL

\section{Refêrencia eletrónica}

José Carlos Miranda e Mariana Leite, "Pedro SÁNCHEZ-PRIETO (coord.), ALFONSO X EL SABIO, General Estoria », Medievalista [Online], 9 | 2011, posto online no dia 02 janeiro 2011, consultado o 22 setembro 2020. URL : http://journals.openedition.org/medievalista/619; DOI : https://doi.org/ 10.4000/medievalista.619

\section{(c) (i) (5)}

Mediavalista está licenciado com uma Licença Creative Commons - Atribuição-NãoComercial 4.0 Internacional 
Titulo: Recensão

ALFONSO X EL SABIO, General Estoria, Pedro SÁNCHEZ-PRIETo (coord.), 10 vol., Madrid: Biblioteca Castro, Fundación José Antonio de

Castro, 2009.

Autor(es): José Carlos Miranda e Mariana Leite

Enquadramento Institucional: Universidade do Porto / Faculdade de Letras

Contacto: mirandajcr@gmail.com / mariana0leite@gmail.com

Fonte: Medievalista [Em linha]. №9, (Dezembro 2010). Direc. José Mattoso. Lisboa: IEM.

Disponível em: http://www2.fcsh.unl.pt/iem/medievalista/

ISSN: 1646-740X

\section{Recensão}

ALFONSO X EL SABIO, General Estoria, Pedro SÁNCHEZ-PRIETO (coord.), 10 vol., Madrid: Biblioteca Castro, Fundación José Antonio de Castro, 2009.

\section{José Carlos Miranda e Mariana Leite}

Por volta de 1270, empreendeu Afonso X, também chamado "o Sábio", filho de Fernando III e de Beatriz de Hohenstaufen da Suábia, um projecto literário de envergadura assaz inusual que consistia em narrar, em língua vulgar castelhana, a história do mundo desde a Criação até ao tempo em que ele mesmo era rei em Leão e Castela e aspirante à condição de imperador do Sacro Império Romano e Germânico. Para o fazer, reuniu uma vasta quantidade de fontes latinas, árabes, hebraicas e em línguas vulgares europeias, que seriam utilizadas como reforço da parte histórica dos 
livros da Bíblia, como espinha dorsal do projecto. Assim nasceria a Grande e General Estoria.

Ao contrário do que se poderia suspeitar, a obra manifesta uma grande preocupação com a credibilidade do relato histórico no seu todo e não tanto intuitos apologéticos relativamente à narrativa bíblica. O objectivo explícito no prólogo é claro: dar conta de todos os feitos acontecidos no passado, notáveis e ignóbeis, acrescentando ao relato historiográfico informações geográficas e naturalistas, e incluindo ainda textos de carácter literário - como o Cântico dos Cânticos - que, pelo seu relevo no corpo da Bíblia, não poderiam ser ignorados por parte de um projecto que visava dar conta da obra de toda a Humanidade. Assim, o procedimento seguido consistiu numa tentativa, de sucesso necessariamente desigual, de compatibilizar cronologicamente eventos da História Sagrada com feitos da História pagã, fazendo desfilar em sintonia, ao longo de seis longas partes mais ou menos correspondentes a outras tantas Idades do Mundo, os patriarcas e reis do Antigo Testamento a par da guerra de Tróia, os cativeiros da Babilónia em paralelo com o império de Alexandre e os Macabeus antecedendo a história política da república de Roma, que comparece através da mais antiga tradução europeia conhecida da Farsália de Lucano.

Em 1284, quando Afonso, o Sábio, morre, a larga equipa de colaboradores que reunira para a realização desta vasta iniciativa de escrita não teria ainda terminado a sua tarefa, do mesmo modo que estaria também activo o conjunto de escribas que com ele havia colaborado na reformulação da Estoria de España, obra igualmente iniciada nos primeiros anos da década de setenta desse século e que tantos pontos de contacto revela com a General Estoria. Como quer que seja, este magno projecto ficou inconcluso, sendo esse aspecto mais visível na sexta e última parte da obra, a qual subsiste apenas num fragmento, copiado posteriormente, de um estádio redactorial provisório.

Não foi até hoje possível averiguar se a General Estoria alguma vez circulou completa fora do círculo régio, ou pelo menos agrupando as cinco partes cujo estado de acabamento foi maior. Tal como sucede com outras extensas obras medievais (o ciclo de romances arturianos em prosa é o que mais se aproxima, tanto na estrutura como na organização material, da capital obra alfonsina), a tradição manuscrita da General Estoria aponta para uma fragmentação que terá ocorrido muito cedo, tendo-se autonomizado os diversos livros que a compunham, o que levou a que cada um deles viesse a ter uma posteridade própria. De facto, unicamente subsistem dois códices 
régios, testemunhos mais próximos, portanto, do projecto inicial: o manuscrito A (BNE 816), que conserva quase integralmente a primeira parte, e o manuscrito U (Vat. Urb. Lat. 539), da quarta parte. Das segunda, terceira, quinta e sexta partes não restam senão manuscritos parciais. Muitos deles, como é o caso dos manuscritos da terceira parte, contêm somente um tipo de matéria, bíblica ou pagã; outros, como acontece com a sexta parte, são apenas rascunhos fragmentários e em mau estado de conservação. Em todo o caso, as questões suscitadas pela circulação e difusão da obra só poderem ser equacionadas perante o conhecimento detalhado do seu conteúdo, ou seja, após a sua edição integral levada a cabo a partir dos testemunhos existentes.

Ora essa edição completa acaba de surgir pela iniciativa de Pedro Sánchez-Prieto Borja, coordenando uma equipa redactorial composta por Belén Almeida, Bautista Horcajada Diezma, Carmen Fernández López, Verónica Gómez Ortiz, Inés Fernández-Ordóñez, Raul Orellana e Elena Trujillo. Com o patrocínio da Fundação José Antonio de Castro, reúnem-se, possivelmente pela primeira vez desde a época em que foram redigidos, todos os livros que contêm a Grande e General Estoria, perfazendo um total de dez volumes e mais de seis mil páginas.

A edição desta obra implicou a adopção de critérios editoriais que favorecessem a sua harmonização interna, já que se trata, como vimos, de uma obra excepcionalmente extensa e servida por uma tradição manuscrita com características de escrita diferenciadas nas diversas partes que a compõem. Além disso, o facto de a fixação do texto das segunda, terceira, quinta e sexta partes decorrer em grande medida da colação entre manuscritos de factura linguisticamente diversa pesou no sentido do emprego de critérios de transcrição regularizadores, contra opções mais próximas da leitura paleográfica que frequentemente se seguem na edição de outros textos medievais.

Assim, nas normas de transcrição adoptadas, os editores propõem-se não só desdobrar abreviaturas - sem contudo as assinalar graficamente - e proceder à usual introdução de pontuação, mas também regularizar nomes próprios e mesmo grafias, cujas modificações, no entanto, não colidem com as características fonéticas do castelhano do século XIII. A estratégia editorial, como parecia impor-se, apontou no sentido de uma edição crítica, não apenas pela selecção de variantes, mas também por sistemáticas intervenções dos editores nos loci considerados problemáticos, com recurso à lição conjectural. Ou seja, procurou-se oferecer uma edição que permitisse uma leitura confortável a um público alargado sem no entanto descurar um aturado trabalho 
filológico através do qual se pôde transmitir as características da escrita alfonsina, que manifestava já um esforço de fixação ortográfica do castelhano do século XIII.

Naturalmente que a primazia concedida à legibilidade e a utilização da prática ecdótica no sentido da obtenção de um texto mais coeso, onde a flexibilidade das regularizações age em detrimento das limitações impostas pelo respeito paleográfico, impede um maior rigor no que concerne à percepção daquilo que é efectivamente transmitido pelos manuscritos, pese embora a utilidade do aparato crítico presente no final de cada volume.

No mesmo sentido, e uma vez que, dentro dos critérios globalmente definidos, foi dada liberdade a cada um dos editores para os adaptar e aplicar conforme as características da parte da obra que editava, em alguns casos as decisões tomadas suscitam reticências, nomeadamente no que diz respeito à inserção de elementos verbais (como preposições, embora sempre graficamente assinaladas), que facilitam a leitura do texto por parte dos receptores actuais, mas não são fundamentais para a sua compreensão. É certo, porém, que a clareza da proposta editorial apresentada no início de cada parte da obra adverte o leitor para que está perante uma versão criticamente trabalhada do que é legível nos manuscritos, uma vez que, para uma leitura paleográfica dos mesmos, existem já as transcrições elaboradas pelo Madison Hispanic Seminary of Medieval Studies.

Não obstante as inevitáveis interrogações e controvérsias que os critérios editoriais sempre levantam, há que olhar para esta edição como um trabalho de irrepreensível labor ecdótico, que coloca o leitor perante um texto credível porque todas as opções são plenamente justificadas. É ainda uma iniciativa imensa e infatigável, levada a cabo com um empenhamento e um entusiasmo tais que se comunicam facilmente ao leitor, constituindo a maior homenagem prestado a Afonso X, e aos atributos que fizerem dele "o Sábio". Acrescente-se ainda a relevância dos estudos introdutórios que acompanham cada uma das partes, outra das grandes mais-valias, sem dúvida, desta edição da Grande e General Estoria. Não se limitando a dar conta das especificidades codicológicas e paleográficas dos manuscritos com que se deparavam, os editores elaboraram análises atentas e cuidadosas, assinalando também fontes, linhas temáticas, características redaccionais e de tradução que em muito enriquecem o já extraordinário feito editorial que esta empresa representou.

Estamos, pois, perante um marco importante da literatura europeia. A primeira história universal redigida em língua vulgar, ultrapassando largamente os projectos idênticos 
existentes na época, torna-se agora disponível a um público alargado mas exigente que deseje conhecer este monumento literário até agora tão esquecido. Subscrevem-se assim integralmente as palavras de Pedro Sánchez-Prieto Borja na introdução geral da obra: «solo la edición íntegra va a permitir a esta historia patrocinada por el rey Alfonso X el Sabio ocupar el lugar que merece entre las letras medievales europeas».

\section{COMO CITAR ESTE ARTIGO}

\section{Referência electrónica:}

MIRANDA, José Carlos; LEITE, Mariana - ALFONSO X EL SABIO, General Estoria, Pedro SÁNCHEZ-PRIETO (coord.), 10 vol., Madrid: Biblioteca Castro, Fundación José Antonio de Castro, 2009. Medievalista [Em linha]. N9, (Dezembro de 2010).

[Consultado dd.mm.aaaa]. Disponível em http://www2.fcsh.unl.pt/iem/medievalista/MEDIEVALISTA9Imiranda-leite9007.html. ISSN 1646-740X.

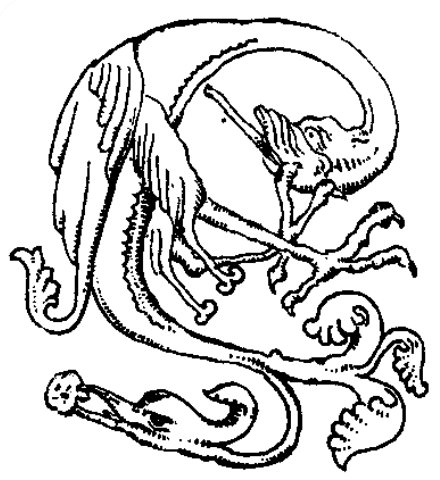

